\title{
Os coreanos na história segundo Bruce Cumings
}

\author{
AMAURY PORTO DE OLIVEIRA
}

Bruce Cumings, autor de Korea's Place in the Sun: A Modern History (New York: W.W. Norton, 1997) é um dos mais respeitados, e provavelmente o mais polêmico, dentre a meia-dúzia de acadêmicos americanos fluentes em coreano e dedicados a estudar a Coréia. A Coréia na sua milenar história e integridade peninsular. Cumings privilegia, no entanto, o século XX, sendo autoridade no evento-mor do período para os coreanos. Sua obra em dois volumes, Origins of the Korean War, permanecerá por muito tempo como o estudo de referência desse conflito.

O livro mais recente de Cumings, ao qual dedicarei este ensaio, tem como público-alvo estudantes universitários da civilização asiática. Aborda, assim, a Coréia não na sua geografia e estatísticas, mas através da longa vivência de um povo unido por ferrenho orgulho nacional. Cumings evidencia grande empatia por esse povo, que é o da sua família política. Sua mulher, Meredith Woo-Cumings, é uma distinta historiadora coreana: Jung-en Woo. Cumings rejeita, contudo, qualquer idéia de uma homogeneidade étnica dos coreanos. Os habitantes da península - acentua ele - são mistura complexa de povos que por ali cruzaram: chineses, japoneses, mongóis e manchus, e talvez até caucasianos. A situação de península e o limite natural com a China, fornecido desde sempre pelos rios Yalu e Tumen, definiram o cadinho em que todos esses grupos se amalgamaram.

Os coreanos costumam remontar a própria história ao terceiro milênio A.C., mas os relatos escritos mais antigos são dos séculos imediatamente anteriores ao início da Era Cristã, quando textos chineses dão conta de pequenos estados, lutando entre si na península. As dinastias chinesas dos Han e dos Tang tentaram mais de uma vez absorver terras da península, mas os reinos locais resistiram tenazmente e, em 618, o Rei de Silla unificou a Coréia, obtendo do Imperador da China que o investisse no novo trono. Até o fim da monarquia coreana, já no século XX, manter-se-ia esse laço de vassalagem do monarca coreano em relação ao chefe do mundo chinês, do qual a Coréia se sentia parte. 
A submissão terminava aí, porém, mantendo os coreanos total autonomia na condução dos seus negócios.

Silla foi reino próspero e de realizações culturais, conforme atesta a magnífica estátua de pedra do Buda, ainda hoje reverenciada na gruta de Sokkuram. Vieram depois as dinastias dos Koryo (918-1392) e dos Choson (1392-1910). O período mais brilhante dessa longa história foi a primeira metade do século XV, sob o Rei Sejong. Os coreanos, que já tinham criado tipos metálicos móveis bem antes de Gutemberg, desenvolveram um alfabeto fonético em substituição aos ideogramas chineses e deixaram preciosos textos budistas. Tomaram também impulso a astronomia, a meteorologia e a cartografia. Cumings utilizou para a capa do seu livro um famoso mapa de 1402, o kanrnido.

O brilho da época do Rei Sejong foi estancado por uma série de invasões devastadoras de manchus e japoneses, bravamente repelidas mas que deixaram a Coréia voltada para si mesma. O país encerrou-se gradualmente num invólucro neoconfucionista, tecido coincidentemente por ideólogos que extirparam a influência política e econômica do Budismo, criando sociedade estática e altamente hierarquizada. A elite todo poderosa era formada pelos sanrbans, figura tipicamente coreana, misto de senhor de terras e doutor em leis, só acessível por herança. As mulheres tiveram seus direitos suprimidos e os deveres estritamente regulamentados. A economia repousava sobre os camponeses, complementados por enorme massa de escravos (30\% da população do país, em alguns momentos). Foi só em 1894 que se aboliu a escravidão na Coréia.

Para o leitor brasileiro interessado em política internacional, o livro de Cumings é a rica e perceptiva reconstituição, a que procede o autor, do jogo politico-estratégico no Nordeste Asiático, nos últimos cento e cinqüenta anos. Por todo esse período, o Nordeste Asiático veio sendo uma das arenas em que se decide o destino do mundo, situação ainda mais intensificada pelo fim da Guerra Fria. Interagem, ali, a China, a Rússia e o Japão, com os EUA interferindo diplomática e militarmente o tempo todo. "Camarão entre as baleias”, como dizem os próprios coreanos, a Coréia só tem sido chamada para pagar contas.

A investida dos países industrializados europeus sobre a Ásia, encetada em meados do século XIX com o propósito declarado de “abrir” os países daquele continente ao comércio internacional, é bem conhecida. As duas “Guerras do Ópio” contra a China. O ultimato do Comodoro Perry ao Japão. As conquistas francesas na Indochina. Um passo mais estava sendo dado na criação do mercado mundial, para a qual a descoberta da América iniciará a 
preparação do terreno, e que vai chegando agora ao auge. Caracteristicamente, os EUA não participaram diretamente da partilha da terra firme asiática. Enquanto os europeus debatiam inclusive a possibilidade de retalhar a China, em antecipação do que fariam mais adiante com a Africa, a vocação imperial dos EUA ia-se manifestando na conquista do Centro-Oeste e Oeste do território americano de hoje, e depois, na absorção de pequenas ilhas e arquipélagos na travessia do Pacífico. Quando esse avanço chegou à Ásia, já os EUA começavam a tomar corpo como o herdeiro visível da hegemonia mundial da Grã-Bretanha. Não lhe era mais necessário disputar a posse de colônias com os outros imperialistas. Seu papel era o de formulador do princípio organizacional que enquadraria a ação de todos. Nos anos 80 do século passado, a produção industrial dos EUA superou a da Alemanha e a da GrãBretanha. Em 1899, as manufaturas já representavam mais de $90 \%$ das exportações americanas para a China. Em consonância com tudo isso, o Secretário de Estado John Hay, a 6 de setembro de 1899, despachou instruções aos Embaixadores americanos em Londres, Berlim e São Petersbugo, para que fizessem chegar notas aos governos perante os quais estavam acreditados, informando-os de que os EUA desejavam ter o apoio deles na condução de uma política de "porta aberta", inclusive nos territórios chineses sobre os quais exercessem eles domínio. Alguns dias mais tarde, notas semelhantes foram enviadas aos governos do Japão, Itália e França.

Contra esse conhecido pano de fundo, Cumings levantou interessante capítulo, descrevendo os desdobramentos não tão notórios da repercussão da investida ocidental no ambiente específico do Nordeste Asiático. Nos três países da sub-região - China, Japão e Coréia -, a primeira reação foram movimentos de revisão da base confucionista dos sistemas imperantes. "Restauração", chamou-se na China; "reconstrução conservadora”, no Japão. ACoréia também teve seu esforço revisor, entre 1864 e 1873, em termos bastante semelhantes aos outros dois, já que nos três casos se tratou de reinterpretar os textos clássicos, à luz de inesperada ameaça externa. Dos três movimentos, apenas o japonês teve futuro, na medida em que evoluiu para a construção de um Estado moderno empenhado em emparelhar-se militar e tecnologicamente com os ocidentais. Os coreanos tentaram a princípio apoiar-se no único poder externo que respeitavam, a China, onde o chefe da diplomacia, Li Hung-chang, que muitos apontam como o maior estadista chinês da segunda metade do século XIX, tentou pateticamente arquitetar tratados entre a Coréia e as potências que a pressionavam, entre as quais não tardou a perfilar-se o Japão. A ilusão contínua de Li era resguardar a independência da Coréia, por mais formal que fosse, mas de maneira a manter a ascendência da China como elo entre a península e o mundo. 
Os esforços de Li foram-se traduzindo em derrotas e no enfraquecimento contínuo da própria China, e na década dos 90 a Coréia esteve reduzida a terreno de disputa entre o Japão e a Rússia, que também entrara em cena no Nordeste Asiático. A pendência agravou-se, levando à guerra nipo-russa de 1905, após a qual a Rússia derrotada reconheceu a supremacia dos “direitos do Japão sobre a Coréia”. Foi isso formalizado num tratado de paz assinado em 1905, em que Theodore Roosevelt atuou como conciliador. O Presidente americano recebeu o Prêmio Nobel da Paz, de 1905, por esse trabalho, e pouco tempo depois trocou notas diplomáticas com o governo japonês, pelas quais os EUA também reconheciam a ascendência do Japão na Coréia, em troca da garantia japonesa de não questionar a transformação das Filipinas em colônia americana (acordo Taft-Katsura). A 29 de agosto de 1910, após obter manu militari a abdicação do monarca reinante na Coréia, o Japão anexou a península como colônia.

Cumings é um dos pioneiros na identificação do domínio colonial japonês, concomitantemente sobre a Coréia e Taiwan, como período-chave para a posterior industrialização desses dois países, e mais amplamente, para a criação das bases da economia regional do Leste Asiático em plena consolidação neste final de século. Seu trabalho mais completo sobre o assunto é o capítulo, "The origins and development of the North East Asian political economy: industrial sectors, product cycles, and political consequences”, em coletânea organizada por Frederic C. Deyo: The Political Economy of the New Asian Industrialism (Ithaca: Cornell University, 1987). No imediato pós-Segunda Guerra Mundial, quando se aferventou o conceito do desenvolvimento econômico, tomou amplitude a tese oriunda dos círculos universitários americanos de que a difusão de capitais (quase obrigatoriamente dos EUA), da ajuda internacional ao desenvolvimento, dos valores culturais democráticos e de instituições políticas e econômicas inspiradas nas do mundo desenvolvido, iria assegurar rapidamente um brilhante futuro para o que se começou a chamar de Terceiro Mundo. Farta literatura foi escrita sobre tudo isso, e as Nações Unidas proclamaram duas Décadas do Desenvolvimento, totalmente infrutíferas. No centro dessa movimentação estava a tendência a ver o mundo como começando de novo sob a oniciente direção de novo centro hegemônico.

Expressão concreta de tal tendência é o debate entre os que explicam o notável êxito dos “novos países industriais” (NPIs) do Leste Asiático como fruto da ação de Estados desenvolvimentistas, capazes de fazer o mercado funcionar em beneficio da economia nacional, e os que só vêem o mercado, tirando valor à ação do Estado. Na quase totalidade, contentam-se esses estudos com a análise de decisões e opções, tomadas no contexto do pós-guerra. Contra 
isso veio a insurgir-se, no tocante ao LesteAsiático, um grupo de estudiosos para quem o esforço de construção econômica nessa região vem apresentando, no presente século, uma integridade fundamental. Para ser bem compreendido, precisa tal esforço ser analisado através da interação dos países da área uns com os outros, e da região com o grande mundo. Tudo isso posto-conforme enfatiza Cumings no trabalho de 1987 - "no contexto de dois sistemas hegemônicos: o Império Japonês até 1945, e a hegemonia intensa, mesmo se difusa, dos EUA, a partir dos anos 40 ”.

O Japão integrou-se, tarde, num grupo de potências imperialistas com séculos de experiência colonial. Para maximizar suas vantagens comparativas, buscou territórios vizinhos, cuja colonização pudesse ser levada adiante em conjunto com a modernização da metrópole. Ao arrepio da velha prática colonial, o Japão levou os meios de produção para trabalhar nas colônias as matérias-primas locais. Portos foram abertos, estradas-de-ferro lançadas e pesados investimentos dedicados às comunicações. Nos anos 30, o Japão se isolou do sistema mundial, dando início com suas colônias - Taiwan, Coréia e Manchúria (anexada em 1932) - a um tipo de desenvolvimento centrado em si mesmo, que gerou altas taxas de crescimento e mudou a face do Nordeste Asiático. Para Cumings, foi nessa década que surgiu ali a “economia natural” hoje patente, e que o Japão começou a tecer o Estado neomercantilista notório.

O ponto sobre o qual Cumings e companheiros estão pondo o dedo vai bem mais fundo do que o surgimento da economia regional do Leste Asiático. O que está em causa, na verdade, é saber se a ascensão da Ásia Oriental a centro mais dinâmico dos processos de acumulação de capital em escala mundial corresponde, efetivamente, a uma troca da guarda no alto comando da economia capitalista mundial. Nessa perspectiva, adquire importância a conclusão de Cumings de que o início de um novo período na industrialização do mundo deve ser datado de meados dos anos 30, no Japão, e não de 1945-50, como se costuma fazer. Tem-se aí problema percuciente e de grande atualidade, mas que escapa aos limites deste ensaio. Ao leitor interessado recomendo o livro de Giovanni Arrighi, $O$ Longo Século $X X$, publicado no Brasil em tradução (São Paulo: Editora UNESP, 1996).

Em Korea's Place in the Sun, Cumings tem um belo capítulo dedicado à fase da colonização japonesa. "O Japão trazia a Coréia em rédea curta sintetiza ele, a certa altura - mantinha-a sob cerrada observação ao mesmo tempo em que ia erguendo um colonialismo organizado, arquitetônico, no qual a figura modelar era o administrador, o planejador, não o conquistador de chanfalho em punho. O Estado forte e altamente centralizado instituído na 
colônia simplesmente repetia o papel que o Estado japonês viera a desempenhar no Japão: intervenção na economia, criação de mercados, lançamento de novas indústrias, supressão de dissidências. Politicamente, os coreanos mal podiam respirar, mas economicamente havia um substancial crescimento, mesmo se desigualmente distribuído.” (p. 148). De 1935 a 1945, a face econômica da Coréia foi marcadamente alterada. O Japão entrara num novo ciclo de industria-lização e começou a transferir para suas colônias (a Coréia e a Manchúria mais do que Taiwan) as parcelas envelhecidas de indústrias como a do ferro e do aço, química e de geração de eletricidade. Massas de camponeses foram arrancados da terra, tomou corpo uma classe operária, o país urbanizou-se e tornou-se grande a mobilidade da população. Não há que ver nisso, contudo, uma efetiva modernização das estruturas sociais da Coréia. Seguia ela sendo, em 1945, sociedade fundamentalmente agrária, na qual os senhores de terras, japoneses e coreanos, mantinham com seus arrendatários relações muito pouco diferentes das do século XIX. E era chocante a ausência de ebulição comercial. ACoréia praticamente não tinha capitalistas. As maiores cidades, inclusive Seul com 370 mil habitantes, não passavam em meados dos anos 30 de centros administrativos.

Fiel aos propósitos do seu livro, Cumings dá nele maior ênfase aos reflexos da colonização japonesa sobre os coreanos, do que à economia política do sistema. A reação permanente dos coreanos foi a de não compactuação com o colonizador e de resistência, inclusive armada quando possível. Nos cinco anos entre o tratado nipo-russo e a anexação de 1910, durante os quais a Coréia foi protetorado japonês, tomou vulto por exemplo a guerrilha: em 1908, estimativas japonesas falavam em quase 70 mil resistentes armados. A maior repressão instalada com o regime colonial dizimou os guerrilheiros, mas um novo surto sobreveio após a anexação da Manchúria, em 1931. Mais de 200 mil combatentes, chineses e coreanos tenuemente coordenados entre si, estiveram ativos num primeiro momento. Já para o fim da década eram uns poucos milhares, com os coreanos como os mais renitentes. Foi nesse meio que emergiu Kim I1 Sung, o futuro lider da Coréia do Norte. Cumings rejeita a mitologia posteriormente criada em torno desse líder (endeusado no Norte e denegrido no Sul), mas salienta a confirmação da importância dele na luta contra os japoneses, atestada por documentos incontestáveis que têm sido localizados nos arquivos do antigo colonizador.

Afora um punhado de colaboracionistas, nos diversos níveis sociais, praticamente só a parcela dos yanrbans que eram senhores de terras aliou-se aos japoneses, situação que iria facilitar a reforma agrária do pós-liberação: os 
latifúndios dos sanrbans seriam tão visados quanto os abandonados pelos japoneses. Os aristocratas ligados à administração do país não seriam, contudo, poupados pelo colonizador. Logo após a anexação, 84 deles foram mandados para casa, juntamente com 3.645 funcionários particularmente ligados à aristocracia. A tomada em mãos da administração da Coréia pelo colonizador foi esmagadora: 246 mil servidores públicos japoneses assumiram o governo de um país de 21 milhões de habitantes. Cumings compara isso com a situação no Vietnã, onde menos de 3 mil administradores franceses governavam 17 milhões de vietnamitas. Privados da condução dos negócios no seu próprio país, os coreanos tornaram-se a mão-de-obra universal do Império japonês. Nos últimos dois anos voltou à baila o problema das mulheres coreanas (200 mil, calcula-se), mobilizadas pelo exército japonês para "confortarem” os soldados. Mas a erradicação de homens e mulheres na faixa entre 15 e 40 anos chegou, nos anos finais da guerra, a $40 \%$ da população da península. Levados para outras províncias da Coréia, para fábricas na Manchúria ou para minas e empresas diversas, no Japão. Em 1941, havia cerca de 1,4 milhão de coreanos trabalhando no Japão e pelo menos 10 mil deles morreram em Hiroxima e Nagasaki.

Na esteira da Primeira Guerra Mundial e das esperanças abertas pelos Quatorze Pontos de Woodrow Wilson, uma vaga democrática percorrera o mundo colonizado. Na China, o movimento estudantil do Quatro de Maio (1919) teve papel de divisor de águas. Os coreanos tiveram o seu Primeiro de Março, também em 1919. Um grupo de trinta e três intelectuais encaminhou ao governo japonês petição reivindicando a independência da península. Nasceram daí manifestações de massa que duraram meses e exigiram a entrada em cena do exército e da marinha japoneses para serem debeladas. A um custo de 7.500 mortos e 45 mil detidos, na contagem dos coreanos. A evidência do descontentamento popular e o clima internacional reinante levaram a administração colonial a pôr em marcha, na Coréia, a chamada "política cultural”, declaradamente dirigida a educar os coreanos para uma distante independência. Começaria aí um interregno de relativa tolerância, que iria durar até a eclosão do fascismo japonês, nos anos 30. Cidadãos coreanos tiveram acesso a universidades e academias militares, podendo até fazer carreira no Exército da Manchúria, como aconteceu com o futuro ditador da Coréia do Sul, General Park Chung-hee. Nesse período, tomaram corpo as concorrentes nacionalista (nas suas vertentes liberal e radical) e comunista, que iriam dominar a vida política no pós-guerra, de um lado e do outro do paralelo 38.

A partição da península foi a expressão local da passagem do Nordeste Asiático, do Império Japonês, para a fase de hegemonia dos EUA. A Ordem Geral Número Um, baixada pelo General Mac Arthur após a rendição japonesa, 
já registrou a divisão da Coréia na altura do paralelo 38, linha escolhida unilateralmente pelos EUA poucos dias antes. As forças americanas de ocupação desceram em Inchon, o porto de Seul, no dia 8 de setembro de 1945, e até hoje há 36 mil militares dos EUA estacionados na Coréia do Sul, no quadro de acordos posteriormente assinados. A Guerra Fria, chegada à Península coreana antes de sua caracterização no resto do mundo, tende a prolongar-se lá após ter sido encerrada.

Violentados na unidade que sustentaram secularmente com tanto esforço, os coreanos vêm agora tentando modelar sua própria história, com a margem de liberdade que lhes vai deixando o grande jogo global. No Norte, o regime encerrou-se numa exacerbada auto-suficiência em que a base marxista foi fortemente tingida pelas tradições neoconfucionistas da Coréia, e vem demonstrando enorme capacidade de sobrevivência, apesar das crescentes dificuldades econômicas que o desmoronamento do "socialismo real", que lhe dava apoio, vem impondo ao país. No Sul, um Estado desenvolvimentista de tipo japonês montou a experiência mais bem sucedida, até agora, de modernização de um país saído das fileiras do Terceiro Mundo. O impulso modernizador tem sido sustentado pelo Estado, mas a tarefa do emparelhamento tecnológico com o mundo industrializado foi entregue a grandes firmas, criadas praticamente do nada, e que hoje buscam independizar-se da tutela estatal.

Essa distinta evolução das duas metades da Coréia é conhecida, em suas linhas gerais. Mas tudo isso é mais política contemporânea do que história. Pontos sujeitos às opiniões de cada um. Suspendo, assim, minha resenha, sugerindo ao leitor que vá ao livro. 